\title{
Investigations of Sound and Carious Dentin Using Ultrasound Velocity and Scanning Electron Microscopy-An Vitro Study
}

\author{
Aziza H Eldarrat* \\ Maktoum Bin Hamdan Dental University College, Dubai, UAE
}

Submission: November 08, 2020; Published: November 12, 2020

*Corresponding author: Aziza H Eldarrat, Maktoum Bin Hamdan Dental University College, Dubai, UAE

\begin{abstract}
Aim: To investigate structural changes in human dentin due to aging process or caries using ultrasound velocity and scanning electron microscopy (SEM).

Materials and Methods: An in-vitro study conducted on human dentin samples. Dentin samples were prepared from the extracted molars using a computerized water-cooled cutting machine. Each sample was $7 \mathrm{~mm}$ long, $5 \mathrm{~mm}$ wide and $2 \mathrm{~mm}$ thick [ $\pm 0.1 \mathrm{~mm}]$. Fifteen dentin samples were prepared for the three experimental groups. Each group consists of five dentin samples. Group 1 (20year old sound dentin), group 2 (50year old sound dentin) and group 3 (carious dentin). Ultrasound velocity measurements were carried-out on dentin samples and the data were compiled and analyzed using Wave Star software and Minitab 12.1 software. After the ultrasonic measurements, the dentin samples were characterized using SEM.
\end{abstract}

Results: Ultrasonic measurements showed that the arrival time of wave signal was $35.1 \mu$ s in 50year old dentin, 35.8 $\mu$ s in 20 year old dentin and $36.4 \mu$ s in carious dentin, and there were significant differences ( $p<0.05$ at $95 \%$ confidence level) in the mean values of the ultrasonic velocity measurements between group 1 and group 2, and between group 2 and group 3. Based on the SEM micrographs, the structural changes can be seen clearly in 50year old dentin due to the aging process and in carious dentin due to caries.

Conclusion: Results indicated that structural changes of human dentin due to aging process and caries can be distinguished using ultrasonic velocity, however, further work is required on larger sample size, intermediate ages and restored teeth.

Keywords: Dentin; Dentin structure; Caries; Scanning electron microscopy; Ultrasound

\section{Introduction}

Ultrasound is a safe, fast, non-invasive and relatively inexpensive technique that has been used extensively in medical imaging for several decades. In the dental field, the use of ultrasound to investigate oral soft and hard tissues is increasing. The early use of ultrasound to visualize internal structures of teeth was initiated a long time ago [1]. Subsequently, several researchers carried out ultrasonic investigations on dental tissues and their results confirmed that ultrasound as tested in-vitro shows considerable promise for the assessment of tooth layers, tooth surface demineralization and types of dentin [2-4]. Recently, ultrasound is being used for early caries detection [5], assessment of sound dentin [6] and enamel thickness [7], visibility of pulp spaces [8], assessment of gingival thickness [9], dental implants placement [10], measurement of bone thickness surrounding implants [11] and accuracy of tooth impressions [12]. Lately, extensive reviews of ultrasound imaging advances in dentistry were published by Marotti et al. [13] and Kocasarac \& Angelopoulos [14]. However, insufficient data is available for the assessment of structural changes in dentin due to the aging process. Dentin is a complex structure in nature and consists of intertubular dentin, dentinal tubules and peritubular dentine. One of the age-related changes in human dentin is the continuous deposition of peritubular dentin on the inner surface of the walls of the dentinal tubules. It begins at the extremities of dentinal 
tubules near the dentino-enamel junction and the tubules become partially or completely occluded with increasing age [15]. Partial and/or complete closure of dentinal tubules with increasing age was demonstrated by using SEM [16].

Dentin caries is caused by cariogenic bacteria, which has the ability to produce acid to demineralize the inorganic component of dentin. The clinical consequence of dentin demineralization is serious, because it decomposes dentin structure by dissolving the minerals of inorganic components and results in widening of the dentinal tubules. As a result of widening of the dentinal tubules, dentin permeability increases to micro-organisms and/or their toxins leading to caries formation and pulpal tissue infections. Thus, probing for a safe and fast technique that enhances the visualization of dentin structure changes due to caries around tooth restorations is considered a subject of interest. Therefore, the aim of this in-vitro study was to investigate primarily the feasibility of ultrasound to detect structural changes in human dentin due to the aging process and caries. The null hypothesis of the current study was incapability of ultrasound to detect structural changes in human dentin.

\section{Materials and Methods}

\section{Teeth collection}

Extracted impacted and caries third molars were used for the current study. The patient's age was known for the molars. The rationale for using impacted sound molars was to avoid the effect of attrition on dentin structure and to confirm structural changes in dentin due to the aging process. Immediately after extraction the teeth were cleaned of soft tissue debris and bone fragments and stored in hermetically sealed vials containing normal saline with a few Thymol crystals and kept at $4{ }^{\circ} \mathrm{C}$. Two age groups ( 20 and 50 years old) were selected for studying the age-related structural changes in sound dentin. A written informed patient consent was obtained prior to extraction.

\section{Sample preparation}

Dentin samples were prepared from the extracted molars using a computerized water-cooled cutting machine equipped with a diamond wheel (Struers Ltd., Glasgow, U.K.). Following a radiographic assessment, the upper surface for each dentin sample was cut under the DEJ and the lower surface above the pulp horns as shown in (Figure 1a \& 1b). Then a rectangular shape having smooth flat surfaces and parallel sides was prepared using a water-cooled cylindrical diamond bur and polishing paper. Each dentin sample was $7 \mathrm{~mm}$ long, $5 \mathrm{~mm}$ wide and $2 \mathrm{~mm}$ thick $[ \pm$ $0.1 \mathrm{~mm}]$. The dimensions of dentin samples were measured using a micrometer screw gauge at three different locations to determine their mean thickness, width and length. Dentin sample thickness was dictated at $2 \mathrm{~mm}$ in order to keep away from pulp horns and dentino-enamel junction to obtain pure dentin sample with a flat and parallel surface free of irregularities and enamel layer. Before conducting the ultrasonic measurements, the prepared dentin samples were examined under a stereomicroscope to confirm absence of cracks or surface irregularities. Fifteen dentin samples were prepared for the three experimental groups in the current study. Five samples were prepared from 20year old molars (group 1), five samples were prepared from 50year old molars (group 2) and five samples were prepared from carious molars (group 3). Samples were kept in a saline solution at $4{ }^{\circ} \mathrm{C}$. The preparation of dentin samples was standard through-out the study.

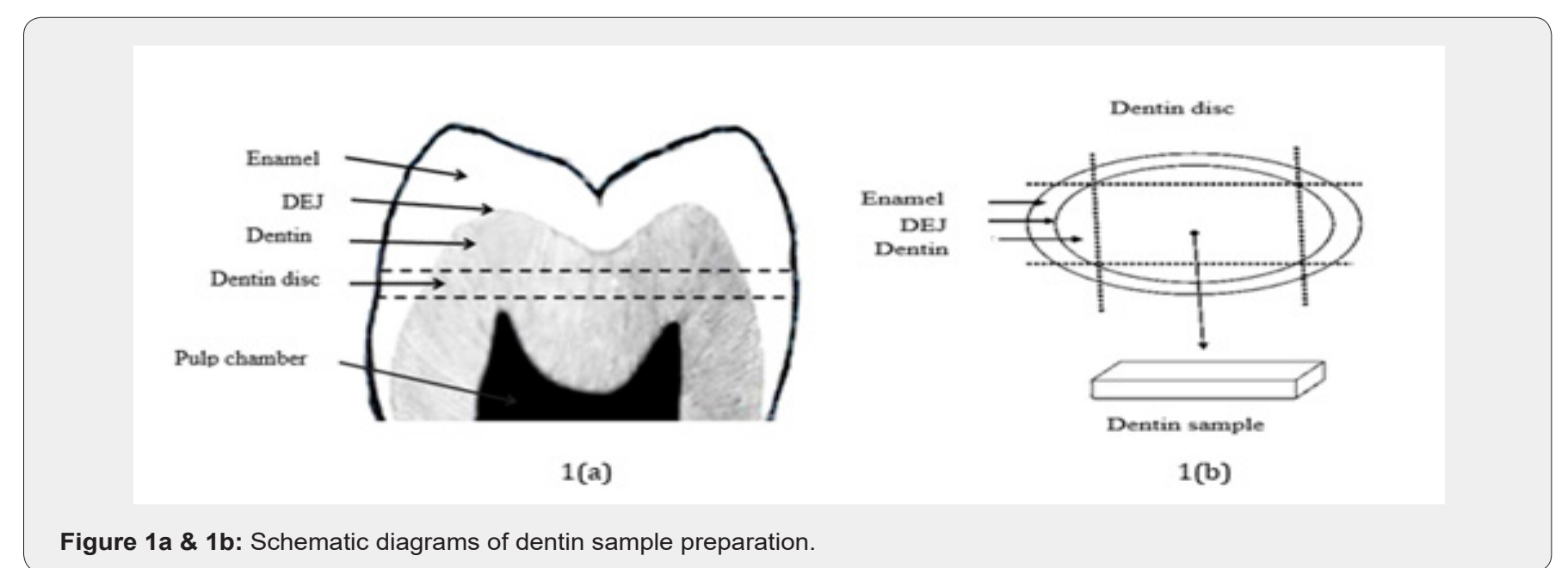

\section{Experimental setup}

The computer controlled experimental setup consisted of an acoustic water tank fabricated from transparent Perspex and two transducers (each with $2.5 \mathrm{MHz}$ frequency). One of the transducers was connected to a pulse generator (pulser) and the other transducer was connected to a $100 \mathrm{MHz}$ digital oscilloscope (Tektronix TDS 220, USA). The digital oscilloscope employs Wave Star software (Tektronix, Inc., USA). The software controls the oscilloscope to capture, display and analyze signal waveforms to obtain numerical values via GPIB, RS-232 or internet connections. 


\section{Sample holder}

A special sample holder was fabricated from polystyrene material to hold the dentin sample between the transducers and to prevent sample movement during the ultrasonic measurements.

\section{Ultrasonic velocity measurements}

The ultrasonic velocity measurements of dentin samples were carried out at 20 ㅇ using the computer controlled experimental set-up [6]. Prior to the ultrasonic measurements, the experimental set-up was validated using calibration phantom. The dentin samples were thawed for at least one hour before ultrasonic measurements, and then each sample was placed in the sample holder and inserted into the acoustic water tank filled with distilled water $\left(\mathrm{ddH}_{2} \mathrm{O}\right)$. The sample holder with the dentin sample was placed in close proximity to the transmitter to ensure that all signals effectively passed through the dentin sample. A five- minute delay before starting ultrasonic measurement was initiated to avoid the effect of water motion on the ultrasonic measurement. Then a signal was generated by the pulse generator and transmitted through the dentin sample. The received signal was transmitted to the digital oscilloscope and saved on the computer. The same procedure was repeated for each dentin sample.

\section{Scanning electron microscopy examination}

After performing all ultrasonic measurements, the dentin samples were examined under Environmental SEM-Philips FEI XL30. Dentin samples were polished on wet P 1200 carborundum paper and washed with $\mathrm{ddH}_{2} \mathrm{O}$. Samples were etched with $35 \%$ $\mathrm{w} / \mathrm{v}$ phosphoric acid for 15 seconds to remove smear layers and again washed with $\mathrm{ddH}_{2} \mathrm{O}$. The pulpal surface was marked for each sample. The samples were dehydrated through graded alcohol containing $50 \% \mathrm{v} / \mathrm{v}, 70 \% \mathrm{v} / \mathrm{v}$ and $90 \% \mathrm{v} / \mathrm{v}$ ethyl alcohol for $30 \mathrm{~min}$ each. This was followed by two immersions in absolute ethyl alcohol for 30 min each in order to avoid tissue shrinkage on direct exposure to absolute alcohol. After drying the samples in graded alcohol, the samples were further desiccated under vacuum overnight at $20^{\circ} \mathrm{C}$. Each sample was mounted on a carbon disc and then securely placed on an aluminum SEM stub.

\section{Statistical analysis}

Minitab for windows, version 12.1 (Minitab Inc, Pennsylvania, USA) (https://www.minitab.com/en-us/), was used in the current study. Minitab is a software package for carrying out statistical, numerical, and graphical calculations. The software was used to perform a t-test and ANOVA test at a confidence level of $95 \%$ to ascertain the differences between the experimental groups were statistically significant.

\section{Results}

Measurements of ultrasonic velocity were carried out on dentin samples and the measurements demonstrated that the arrival time of wave signal was $35.1 \mu$ s in 50year old dentin, $35.8 \mu$ s in 20year old dentin and $36.4 \mu$ s in carious dentin using Wave Star software. Mathematical calculations of the ultrasound velocity measurements using the computer software were carried out and the results are shown in Figure 2 for group 1 (20year old dentin), group 2 (50year old dentin) and group 3 (carious dentin). The figure shows the mean values of ultrasound velocity measurements of five samples for each group. Ultrasound velocity measurements showed that there were significant differences in ultrasound velocity between group 1 and 2, and between group 2 and group 3 ( $p<0.05$ at $95 \%$ confidence level). After ultrasonic measurements, dentin samples were characterized using SEM. The SEM micrographs of 20year old dentin, 50year old dentin and carious dentin are shown in Figure 3-5, respectively. Based on the SEM micrographs, the structural changes can be seen clearly in dentin samples due to the aging process and the caries disease.

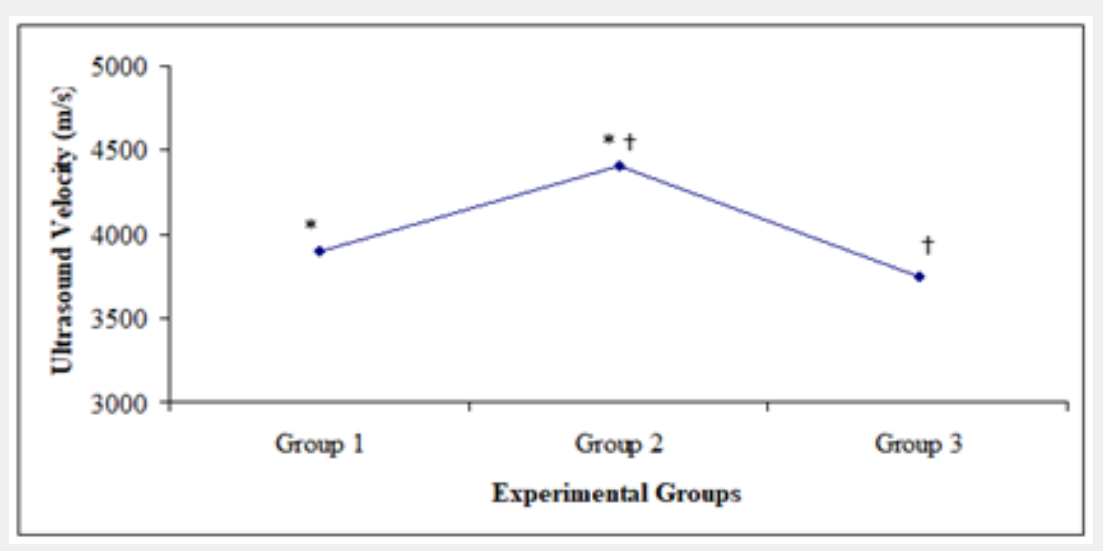

Figure 2: Ultrasound velocity measurements of the experimental groups [group 1 (20year old dentin), group 2 (50year old dentin), group 3 (carious dentin)]. ( $\left.{ }^{*}\right)$ Indicates significant difference between group 1 and group $2(p<0.05$ at $95 \%$ confidence level) and $(\dagger)$ indicates significant difference between group 2 and group $3(p<0.05$ at $95 \%$ confidence level) 


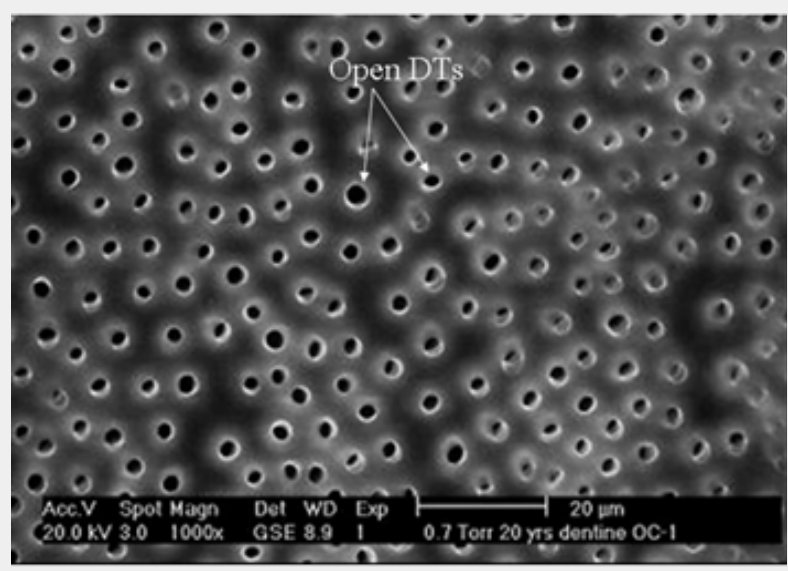

Figure 3: Electron micrograph scan of 20year old dentin (DTs, Dentinal tubules).

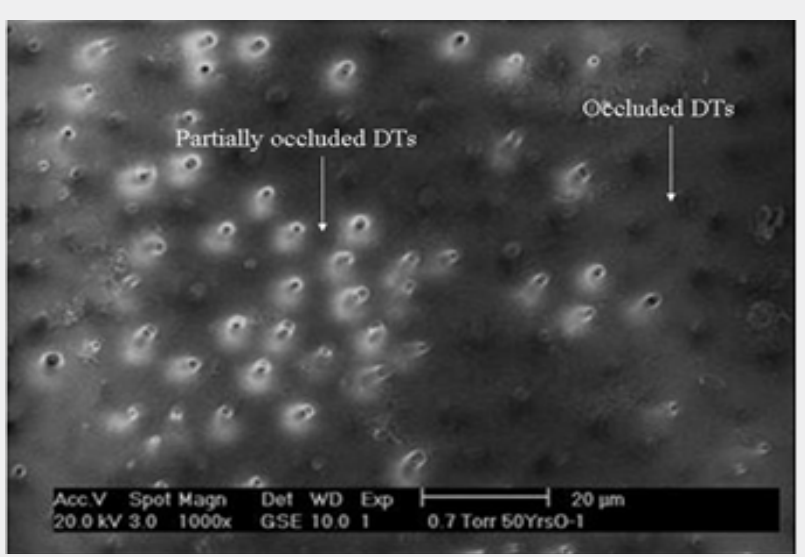

Figure 4: Electron micrograph scan of 50year old dentin (DTs, Dentinal tubules).

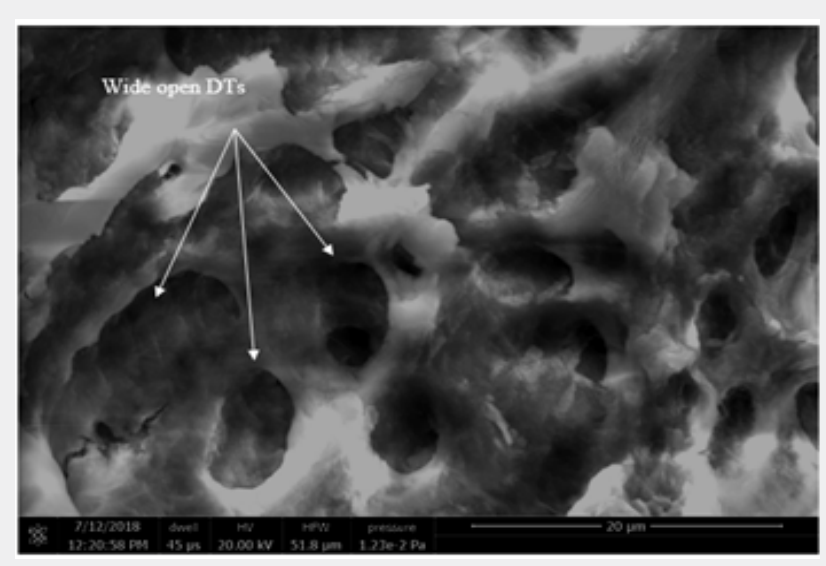

Figure 5: Electron micrograph scan of carious dentin (DTs, Dentinal tubules).

\section{Discussion}

The use of ultrasound to investigate dental tissues is increasing and the results of these investigations have shown that ultrasound has a promising future for dental applications. Several studies have been assessing ultrasound velocity on dentin samples, but none of these studies have considered the influence of structural changes due to aging process or caries on the experimental work. In the literature, different values of ultrasound velocity in dentin were reported by the earlier studies. The ultrasound velocity values were found to be $3870 \pm 300 \mathrm{~m} / \mathrm{s}$ by Maev et al. [4], $4000 \mathrm{~m} / \mathrm{s}$ by Kossoff and Sharpe [17], $3800 \pm 370 \mathrm{~m} / \mathrm{s}$ by Barber [18], $4050 \pm$ $30 \mathrm{~m} / \mathrm{s}$ by Ng SY [19] and $2800-4300 \mathrm{~m} / \mathrm{s}$ by Löst [20]. 
In the current study, the ultrasound velocity measurements of dentin samples showed that the arrival time of wave signal was $35.1 \mu$ s in 50year old dentin, $35.8 \mu \mathrm{s}$ in 20 year old dentin and $36.4 \mu \mathrm{s}$ in carious dentin. The arrival time of wave signal indicates that the wave signal travels faster in sound older dentin than in young dentin and carious dentin. The mean values of the mathematical calculations of the ultrasound velocity measurements in dentin samples were found to be $4400 \pm 30 \mathrm{~m} / \mathrm{s}$ in 50 year old, $3900 \pm 24 \mathrm{~m} / \mathrm{s}$ in $20 y e a r$ old and $3750 \pm 55 \mathrm{~m} / \mathrm{s}$ in carious dentin, in this study. One-way ANOVA test of the mean values of ultrasound velocity measurements revealed a significant difference $(\mathrm{P}<$ 0.05 at $95 \%$ confidence level) between 20year old and 50year old dentin and between 50year old dentin and carious dentin. However, there was no significant difference $(\mathrm{P}<0.09$ at $95 \%$ confidence level) between 20year old dentin and carious dentin. The current results explain the reason for the different values of ultrasound velocity in dentin were reported by the earlier studies and show that ultrasound has the capability to distinguish the changes in dentin structure. Similar results were demonstrated by two in-vitro studies. In the first study, the researchers investigated structural changes of bone, which is similar to dentin, using ultrasound velocity and showed that when the porosity of bone decreased, there was a significant increase in ultrasound velocity [21]. In the second study, the ultrasound velocity was found to be slower in coronal dentin $(3903 \mathrm{~m} / \mathrm{s})$ than that in radicular dentin (4226m/s) [22].

Having been careful to fully validate the method by examining and comparing the original pulse-echo characteristics of the ultrasound transducer before and after the insertion of sample holder and the pulse-echo characteristics of ultrasound after passing through dentin sample [6], the differences between young and old dentin are believed real and indicated that the ultrasound velocity in older dentine is faster than that in younger dentin. This can be explained by the continuous deposition of peritubular dentin on the inner walls of dentinal tubules, which is known to reduce the diameter of dentinal tubules, eventually leading to complete closure of tubules with increasing age. In effect, the young dentin consists of inter tubular dentin, peritubular dentin and dentinal fluid in widely open dentinal tubules. Whilst older dentin has the same components, there is much more peritubular dentin in occluded tubules, and consequently less dentinal fluid.

As a result of continuous deposition of peritubular dentin in older dentin, the inorganic component increases, and the structure becomes more homogenous and less porous than young dentin. It can be clearly seen in Figure 3 that dentinal tubules are widely opened and distributed all over the surface of young dentin, whereas in old dentin, most dentinal tubules are partially or fully occluded by peritubular dentin deposition (Figure 4). In carious dentin, ultrasound velocity was found to be the slowest $(3750 \pm 55 \mathrm{~m} / \mathrm{s})$ compared to sound old and young dentin. It is well documented that caries rigorously damages dentin structure by severe demineralization of the inorganic part and widening of dentinal tubules, as is clearly shown in the SEM micrograph (Figure 5). This study was the first to investigate the capability of ultrasound to distinguish structural changes due to the aging process and caries in human dentin. Within the limitations of the current study, the primary results showed that structural changes of human dentin can be distinguished by using ultrasound velocity and thus the proposed null hypothesis was rejected.

\section{Conclusion}

The results indicated that structural changes of human dentin due to aging process and caries can be distinguished using ultrasound velocity, however, further work is required on a larger sample size, intermediate ages and restored teeth.

\section{Clinical Significance}

A safe and fast method based on ultrasound measurements, that enhances the visualization of dentin structure changes, could has a significant potential as diagnostic tools for dentin structure analysis and early secondary caries detection in the future.

\section{Acknowledgement}

The author is grateful to Dr. Fuad Tarbah, Director of Training and Development Department, Dubai Police for his help and support with the SEM investigations, and Mr. Stephen Palubiski, Lecturer at English Language College, University of Sharjah, for his careful reading and editing of this article.

\section{References}

1. Baum G, Greenwood I, Slawski S, Smirnow R (1963) Observation of internal structures of teeth by ultrasonography. Science 139(3554): 495-496.

2. Lees S, Barber FE (1968) Looking into teeth with ultrasound. Science 161(3840): 477-478.

3. Lees S, Barber FE, Lobene RR (1970) Dental enamel: detection of surface changes by ultrasound. Science 169(3952): 1314-1316.

4. Maev RG, Denisova LA, Maeva EY, Denissov AA (2002) New data on histology and physico-mechanical properties of human tooth tissue obtained with acoustic microscopy. Ultrasound Med Biol 28(1): 131136.

5. Kim J, Shin TJ, Kong HJ, Hwang JY, Hyun HK (2019) High-Frequency Ultrasound Imaging for Examination of Early Dental Caries. J Dent Res 98(3): 363-367.

6. Eldarrat A (2019) Ultrasonic characterization of human dentine. OAJDS 4(5): 238-244.

7. Sindi KH, Bubb NL, Gutteridge DL, Evans JA (2015) In vitro enamel thickness measurements with ultrasound. Ultrasound Med Biol 41(1): 301-308.

8. Szopinski KT, Regulski P (2014) Visibility of dental pulp spaces in dental ultrasound. Dentomaxillofac Radiol 43(1): 20130289.

9. Slak B, Daabous A, Bednarz W, Strumban E, Maeva RG (2015) Assessment of gingival thickness using an ultrasonic dental system prototype: A comparison to traditional methods. Ann Anat 199: 98103. 
10. Choi M, Culjat M, Singh R, White S (2012) Ultrasound imagery for dental implant diagnosis and treatment planning in a porcine model. J Prosthet Dent 108(6): 344-353.

11. Marotti J, Neuhaus S, Habor D, Bohner L, Heger S, et al. (2019) Highfrequency ultrasound for assessment of peri-implant bone thickness. J Clin Med 8(10): 1539-1550.

12. Chuembou Pekam F, Marotti J, Wolfart S, Tinschert J, Radermacher K, et al. (2015) High-frequency ultrasound as an option for scanning of prepared teeth: an in vitro study. Ultrasound Med Biol 41(1): 309-316.

13. Marotti J, Heger S, Tinschert J, Tortamano P, Chuembou F, et al. (2013) Recent advances of ultrasound imaging in dentistry-a review of the literature. Oral Surg Oral Med Oral Pathol Oral Radiol 115(6): 819-832.

14. Demirturk Kocasarac H, Angelopoulos C (2018) Ultrasound in Dentistry: Toward a Future of Radiation-Free Imaging. Dent Clin North Am 62(3): 481-489.

15. Chandra S, Chandra, M, Chandra, G, Chandra N (2010) Textbook of dental \& oral histology with embryology \& mcqs. Jaypee Brothers Medical Publishers (P) Ltd.
16. Eldarrat AH, High AS, Kale GM (2010.) Age-related changes in acimpedance spectroscopy studies of normal human dentine: further investigations. J Mater Sci Mater Med 21(1): 45-51.

17. Kossoff G, Sharpe CJ (1966) Examination of the contents of the pulp cavity in teeth. Ultrasonics 4: 77-83.

18. Barber FE, Lees S, Lobene RR (1969) Urasonic pulse-echo measurements in teeth. Arch Oral Biol 14(7): 745-760.

19. Ng SY, Payne PA, Cartledge NA, Ferguson MW (1989) Determination of ultrasonic velocity in human enamel and dentine. Arch Oral Biol 34(5): 341-345.

20. Löst C, Irion KM, John C, Nussle W (1992) Two-dimensional distribution of sound velocity in ground sections of dentin. Endod Dent Traumatol 8(5): 215-218.

21. Tavakoli MB, Evans JA (1992) The effect of bone structure on ultrasonic attenuation and velocity. Ultrasonics 30(6): 389-395.

22. John C (2004) The corono-apically varying ultrasonic velocity in human hard dental tissues. J Acoust Soc Am 116(1): 545-556.

\section{Your next submission with Juniper Publishers}

\section{will reach you the below assets}

- Quality Editorial service

- Swift Peer Review

- Reprints availability

- E-prints Service

- Manuscript Podcast for convenient understanding

- Global attainment for your research

- Manuscript accessibility in different formats

( Pdf, E-pub, Full Text, Audio)

- Unceasing customer service

Track the below URL for one-step submission https://juniperpublishers.com/online-submission.php 